\title{
Ensino de Microbiologia e a Experimentação no Ensino Fundamental
}

\author{
Terimar Ruoso Moresco ${ }^{1}$ \\ Nilda Vargas Barbosa² \\ João Batista Teixeira da Rocha ${ }^{3}$
}

\begin{abstract}
Resumo
Com este estudo objetivamos explorar a eficiência do uso da experimentação para o aprendizado de conceitos sobre microrganismos. Uma oficina com seis atividades experimentais foi realizada com 70 alunos do Ensino Fundamental. Os temas abordados foram conceituação, nutrição, ubiquidade, antimicrobianos, importância e observação dos microrganismos. A eficiência dessa estratégia foi avaliada por meio de respostas a questionários aplicados antes e depois da oficina. As explicações dos estudantes foram analisadas e categorizadas conforme 0 grau de entendimento em N0, N1 N2 e N3. Com essa análise observamos que as aulas experimentais foram eficientes para o ensino sobre os microrganismos, melhorando em 66,67\% o desempenho dos estudantes. Atividades experimentais, portanto, são estratégias indispensáveis para melhorar o aprendizado de microbiologia. Em consequência, legitimamos a necessidade de organização de espaços adequados e 0 aperfeiçoamento dos professores para a real efetivação desse tipo de prática nas escolas.
\end{abstract}

Palavras-chave: Educação em microbiologia. Experimentação. Estratégia didática. Ensino Fundamental.

1 Professora-doutora, Departamento de Ciências da Saúde - Universidade Federal de Santa Maria - Palmeira das Missões, RS. terimarm@ hotmail.com.

2 Professora-doutora, Departamento de Biologia Molecular. Universidade Federal de Santa Maria, RS.nbarbosa@yahoo.com.br

3 Professor-doutor do Programa de Pós-Graduação em Educação em Ciência Química da Vida e Saúde - Universidade Federal de Santa Maria, RS. jbrocha@gmail.com. 


\section{MICROBIOLOGY TEACHING AND EXPERIMENTS IN ELEMENTARY EDUCATIONABSTRAT}

With this research we aim to explore the efficiency of experimentation to learn concepts about microorganisms. A workshop with six experimental activities was carried out with 70 elementary students. The topics covered were conceptualization, nutrition, ubiquity, antimicrobials, importance and observation of microorganisms. The effectiveness of this strategy of learn was assessed through questionnaire responses before and after the workshop. The explanations of the students were analyzed and categorized according to the degree of understanding in N0, N1 N2 and N3. With this analysis, we observed that the experimental classes were efficient for learning about microorganisms, improving the students' performance in this content by $66.67 \%$. Therefore, experimental activities are indispensable strategies to improve the learning about microorganisms. As a consequence, we legitimize the need to organize adequate spaces and improve the teachers for the real implementation of this type of practice in schools.

Keywords: Microbiology education. Experimentation. Didactic strategy. Elementary school.

Recebido em: 21/11/2016

Aceito em: 7/8/2017 
Muito temos debatido sobre a situação da educação em nosso país e reconhecemos que existe uma grave crise em todos os níveis do sistema educacional. As avaliações do Programme for International Student Assessment (Pisa) refletem e respaldam essa preocupação. Na avaliação de Ciências, do ciclo de 2015, 56,6\% dos estudantes demonstraram ter letramento científico restrito, ou seja, "ter conhecimento científico tão limitado que pode ser aplicado apenas a algumas poucas situações conhecidas" (ORGANISATION..., 2016).

Entre as várias áreas da ciência, a microbiologia permeia o cotidiano, uma vez que os microrganismos são ubíquos e exercem incontáveis influências na sociedade: são importantes para a sustentabilidade do ecossistema global (BODELIER, 2011) e para a saúde e a sobrevivência dos seres humanos (ROBERTSON-ALBERTYN; HARDEE; STANLEY-WALL, 2016; CONSORTIUM, 2012); são responsáveis por doenças e perdas econômicas (FISHER, 2012); são a raiz da árvore da vida e a matriz que suporta a biosfera. É imperativo, portanto, educar os jovens para compreenderem sobre os microrganismos e suas relações (SCHAECHTER; KOLTER; RILEY-BUCKLEY, 2004).

A Sociedade Americana de Microbiologia (ASM), traçando as diretrizes para o século 21, destaca entre as suas prioridades a necessidade de promover o letramento sobre os microrganismos. Devido a sua característica "invisível", os microrganismos são entidades abstratas e, em grande parte, ausentes na conceituação da natureza (BARBERÁN et al. , 2016), o que justifica a necessidade de incorporá-los nessas narrativas. Tal abstração implica abordagens de ensino expositiva, teórica, livresca, descontextualizada e desinteressante (NETO; FRACALANZA, 2003; AZEVEDO; SODRÉ, 2014). Assim, apesar da relevância dos microrganismos, os alunos demonstram apenas conhecimento de senso comum, sendo incapazes de explicar o mundo microbiano ao seu redor usando o óculo da ciência (BYRNE; SHARP, 2006; SILVA; BASTOS, 2012; CARNEIRO, 2012; MAFRA; LIMA; CARVALHO, 2013; CÂNDIDO et al., 2015).

Entre as várias estratégias de ensino estudadas a fim de melhorar a aprendizagem, a experimentação tem sido destacada por promover maior envolvimento dos estudantes com a ciência (HOFSTEIN; LUNETTA, 2004; GALIAZZI; GONÇALVES, 2004; CARVALHO, 2004; FOLMER, 2009; RO- 
CHA, 2005; DELIZOICOV; ANGOTTI, 1990). Várias, entretanto, são as causas de o ensino por experimentação não ser frequente nas escolas. Entre as causas mais lembradas pelos professores estão a falta de conhecimento disciplinar, a falta de tempo, a ausência de laboratórios, a carência de material e o número elevado de estudantes por turma.

A participação ativa do aluno no processo de construção do conhecimento, tendo o professor como mediador, marcou a postura do ensino construtivista. Essa participação ativa do estudante no seu aprender desenvolve nele habilidades cognitivas de: resolver situações problemáticas, predizer respostas, testar hipóteses, argumentar, discutir com os pares, podendo atingir a compreensão do conteúdo.

De acordo com Piaget e Delval (1970), nos anos finais do Ensino Fundamental, as crianças estão em transição entre as fases operatório-concreto e operatório-formal do desenvolvimento cognitivo e já apresentam condições cognitivas de realizar aula experimental. Essa estratégia de ensino pode promover o "desequilíbrio cognitivo" necessário para a aprendizagem. Rejeitar o uso de aulas experimentais pode representar um subaproveitamento das capacidades do aluno. Com efeito, na fase operatório formal, o sujeito inicia o pensamento hipotético-dedutivo e torna-se capaz de desenvolver raciocínio experimental, uma vez que é capaz de dissociar fatores isolando uma das variáveis para estudar seu efeito (PIAGET; DELVAL, 1970). Muitos intérpretes da obra de Piaget inferiram que o trabalho com objetos concretos (fornecido em experiências práticas) é uma parte essencial do desenvolvimento do pensamento lógico, principalmente na fase prévia ao desenvolvimento de operações formais (HOFSTEIN; KIND, 2012).

Para ter sucesso, a experimentação deve ser bem planejada, com objetivo definido e embasamento teórico. Os conhecimentos microbiológicos são construtos teóricos e, assim, os experimentos sempre estarão vinculados às teorias, pois tais construtos não são observáveis, mas interpretáveis, previsíveis ou inferíveis (GALIAZZI; GONÇALVES, 2004). Nos documentos oficinais, essa metodologia tem sido explicitada como forma de construção de conteúdos procedimentais, tão importantes quanto os conceituais (GALIAZZI, 2001; BRASIL, 1997). 
As aulas experimentais podem ser do tipo aberta, quando o estudante ajuda a organizar o experimento (ROCHA, 2005), ou estruturada, quando o aluno recebe um protocolo com passos predeterminados (HOFSTEIN; KIND, 2012). Ao oferecer um protocolo definido ou guia de experimento, os desafios estão em interpretá-lo, organizar e manipular os materiais, observar os resultados e checá-los com os esperados (BRASIL, 1997, p. 123).

Considerando o limitado letramento científico sobre ciências dos jovens brasileiros, particularmente sobre os microrganismos, nosso objetivo com este trabalho foi explorar a eficácia da experimentação como proposta pedagógica para a aprendizagem sobre os microrganismos.

\section{Metodologia}

A oficina Micromundo é uma sequência de aulas experimentais sobre os microrganismos, realizada com estudantes do Ensino Fundamental de escolas públicas. A avaliação da eficiência da aprendizagem foi realizada por meio da análise e categorização das respostas aos pré e pós-testes.

Sujeitos: Quatro grupos de estudantes contribuíram para esse trabalho: duas turmas de $6^{\circ}$ ano e duas turmas de $8^{\circ}$ ano de duas escolas públicas do interior do Rio Grande do Sul, totalizando 70 estudantes. A Escola 1, de Ensino Fundamental, Médio Politécnico e Magistério, localiza-se no centro da cidade, atende aproximadamente 800 alunos e seu Ideb é 4,9 (INSTITUTO..., 2016), o Indicador de Nível Socioeconômico (Inse) é alto e o indicador de formação docente é 51 (INSTITUTO..., 2016). A Escola 2, de Ensino Fundamental, localizada em um bairro da periferia, recebe aproximadamente 370 alunos e seu Ideb é 4,1 (INSTITUTO..., 2016). As equipes diretiva e de professores foram consultadas e aceitaram participar do projeto, assinando um convênio com o grupo pesquisador. Por meio de um termo de consentimento, obtivemos a concordância dos responsáveis pelos estudantes para que eles participassem do projeto. 
Por meio de consulta ao Projeto Político-Pedagógico (PPP) das escolas, verificamos que o ensino dos "Seres Vivos" ocorre no $7^{\circ}$ ano. Optamos por realizar a oficina antes de os estudantes terem contato formal com esse conteúdo ( $6^{\circ}$ ano) e após seu ensino ( $8^{\circ}$ ano).

Pré e pós-testes: Sete blocos de questões compuseram o instrumento, com cada bloco buscando um entendimento conceitual específico. O instrumento foi validado por meio da discussão com três professores universitários de microbiologia e um pedagogo de uma das escolas. O escore geral dos validadores foi 50, nota considerada máxima. Entre os professores, dois consideraram as questões pertinentes e afirmaram que os alunos conseguiriam respondê-las, uma vez que os conhecimentos em teste foram trabalhados desde o $6^{\circ}$ ano, ainda que não com a mesma profundidade de um especialista. Um professor achou algumas questões complexas, apontando dificuldades que os alunos poderiam enfrentar para respondê-las. Os estudantes responderam ao pré-teste na semana anterior ao início da oficina e ao pós-teste um mês após o seu término. Com o objetivo de produzir padrões de explicação, categorizamos os dados seguindo as orientações propostas para análise de conteúdo de Bardin (2011). Os dados coletados foram analisados utilizando o Statistical Package for the Social Sciences (SPSS).

As categorias propostas demonstram um nível crescente na compreensão dos conceitos sobre os microrganismos. Nível 0 (N0) - grupo com respostas incorretas ou em que os estudantes responderam "não sei" ou não responderam. Nível 1 (N1) - grupo com respostas que demonstraram conhecimentos obtidos a partir de vivências diárias, diretamente ligados aos objetos concretos do mundo, concepções espontâneas. Nível 2 (N2) - grupo com respostas em que os estudantes manifestam algum nível de entendimento, com respostas parcialmente corretas ou com uso de palavras inadequadas. Nível 3 (N3) - grupo com respostas que demonstram algum nível de abstração e generalização, com linguagem científica adequada, cuja compreensão aproxima-se daquelas descritas na literatura científica. Em questões cujas respostas eram "sim" ou "não", foi atribuído zero (0) à resposta incorreta e um (1) à resposta correta. Realizamos 
teste não paramétrico de Wilcoxon para amostras relacionadas e, para amostras não relacionadas, utilizamos o teste de Mann-Whitney, considerando como significante para $\mathrm{p} \leq 0,05$.

\section{Realização da Oficina}

Realizamos quatro aulas (encontros) de dois períodos cada. Três aulas aconteceram na escola e uma no laboratório de microbiologia da Universidade Federal de Santa Maria (Tabela 1). A maioria dos experimentos precisou de um tempo mínimo de 24 horas entre o momento da sua realização e o momento da observação e discussão dos resultados devido à espera pelo crescimento dos microrganismos. Assim, o experimento foi realizado em uma aula e a discussão, na aula seguinte.

Tabela 1 - Cronograma da Oficina Micromundo

\begin{tabular}{|c|c|}
\hline Aula & Experimento \\
\hline \multirow[t]{2}{*}{$1^{\text {a }}$ aula } & Experimento 1. De onde surgem os microrganismos? \\
\hline & Experimento 2. Do que se alimentam os microrganismos? \\
\hline \multirow[t]{3}{*}{$2^{\mathrm{a}}$ aula } & Discussão dos Resultados do Experimento 1 \\
\hline & Experimento 3. Microrganismos no ambiente \\
\hline & Experimento 4. Como podemos matar os microrganismos? \\
\hline \multirow[t]{2}{*}{$3^{\mathrm{a}}$ aula } & Discussão dos Resultados dos Experimentos 1 e 2 \\
\hline & Experimento 5. Fermentação \\
\hline $4^{\mathrm{a}}$ aula & Observação de microrganismos ao microscópio \\
\hline
\end{tabular}

Fonte: Elaborada pelo autor.

\section{Descrição das aulas realizadas durante a oficina}

Cada experimento seguiu uma estrutura didática organizada em três fases:

$1^{a}$ Fase - Contextualização - Por meio de questionamentos sobre situações cotidianas, buscamos entender as concepções, vivências e dúvidas dos estudantes sobre os microrganismos. As concepções espontâneas foram con- 
sideradas no entendimento de suas limitações e na interação com os conceitos científicos sobre os microrganismos. Nessa fase o aluno percebe a necessidade de adquirir outros conhecimentos para resolver problemas cotidianos. Essa discussão aconteceu tendo como referência implícita o problema associado com a aula experimental que se seguiu, bem como o conhecimento gerado como resposta a esse problema.

$2^{\mathrm{a}}$ Fase - Experimentação - Nessa fase o aluno realizou o experimento para estudar um problema específico. Organizamos o material nas bancadas e cada grupo de três alunos conduziu o seu experimento, sempre com a supervisão de um monitor. Inicialmente orientamos o trabalho para o grande grupo, utilizando o quadro negro e demonstrando as técnicas de manipulação mais complexas. Em seguida cada grupo recebeu um Roteiro da Aula, impresso, contendo as orientações para o registro e discussão dos resultados.

$3^{\text {a }}$ Fase -Discussão dos resultados - Os alunos receberam o material dos seus experimentos, fizeram as anotações que julgaram pertinentes e discutiram os resultados com o pequeno grupo. Por fim, cada grupo socializou sua conclusão e respondeu à questão inicial. Os conhecimentos necessários ao entendimento do experimento e os conhecimentos prévios foram postos em confronto e organizados em conjunto para a compreensão do problema em questão.

Em uma das escolas a oficina aconteceu no laboratório. Na outra os experimentos foram feitos na sala de aula, na qual foram organizadas bancadas com as classes. Todo o material e os reagentes foram fornecidos pelos pesquisadores, uma vez que nenhuma das escolas dispunha de tal material. Para prevenir acidentes utilizamos material plástico, microrganismos não patogênicos e reforçamos a importância dos cuidados para a manipulação segura do material durante os experimentos.

Os experimentos foram sistematizados para construir com o aluno o entendimento de que os microrganismos são seres vivos formados por células, são invisíveis a olho nu, ubíquos e congregam vários grupos de seres vivos, nutrem-se principalmente de matéria orgânica, o seu crescimento está condicionado a uma série de fatores físicos e químicos e são seres vivos importantes para a manutenção da vida no planeta. 


\section{Resultados e Discussão}

Para verificar a eficácia da Oficina Experimental Micromundo, foram analisadas as respostas dos estudantes aos testes pré e pós-oficina. Assim sendo, a análise dos resultados dos 140 testes ( 70 pré e 70 pós-testes) é exposta em sete blocos de questões. Cada bloco contém questões relacionadas ao entendimento de um determinado conceito.

\section{BLOCO 1 - Existência de seres vivos microscópicos}

Um conhecimento fundamental para a conceituação da natureza é o de que existem muitos seres vivos que não somos capazes de enxergar sem a utilização de equipamentos especiais. Antes da oficina, 17,1\% dos estudantes acreditavam na inexistência de seres vivos invisíveis a olho nu. Após a oficina, esse percentual caiu para 12,9\%. O percentual de estudantes que soube exemplificar esses seres aumentou de 50\% para 68,6\% $(p=0,004)$ após a oficina (Figura 1). Os exemplos também foram mais complexos: enquanto antes da oficina os estudantes somente citaram micróbios e bactérias, após outros exemplos foram lembrados, tais como microrganismos, fungos, fermento, vírus e protozoários. O termo microrganismo, que havia sido citado por $13 \%$ dos estudantes, passou a ser lembrado por $44 \%$ no pós-teste.

Embora durante a oficina não tenha sido realizado nenhum experimento específico sobre higiene, houve aprendizagem sobre a relação entre procedimentos cotidianos de higiene e os microrganismos (Figura 1).

Após a oficina, a maioria $(65,7 \%)$ dos estudantes vinculou a necessidade de diminuir a carga microbiana da pele, dentes e mucosas com a rotina de higiene pessoal. Antes da oficina, apenas $35,7 \%$ dos alunos haviam feito essa relação ( $p=0,031)$, concordando com os dados de Goldschmidt et al. (2015) de que as crianças aprendem por repetição, mas não necessariamente compreendem a verdadeira importância de manter os hábitos aprendidos. 
Figura 1 - Entendimento sobre exemplos de seres vivos microscópicos e relação entre higiene e microrganismos

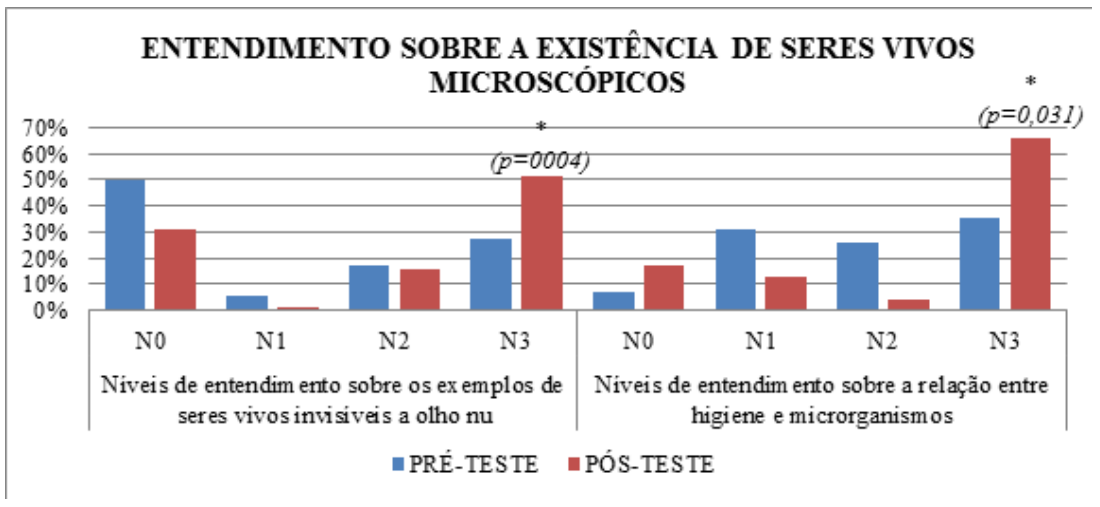

Fonte: Pesquisa com estudantes do Ensino Fundamental. Autoria própria

Dados apresentados a partir do percentual de respostas em cada categoria $\left(\mathrm{N} 0, \mathrm{~N} 1, \mathrm{~N} 2\right.$ e N3) nos pré-teste e pós-teste. $\mathrm{n}=70 .{ }^{*} \mathrm{p}<0,05$ em relação ao pré-teste.

BLOCO 2 - Conceito de microrganismos, micróbios e relação entre eles:

Conforme mostra a Figura 2, no pré-teste, a maioria dos estudantes não soube descrever o conceito de micróbios $(65,7 \%)$, microrganismos $(62,9 \%)$ e a relação entre eles (92\%). Essas respostas foram agrupadas no N0 e não houve diferença significativa entre as respostas dos estudantes do $6^{\circ}$ e do $8^{\circ}$ anos. As respostas agrupadas no N1 demonstraram entendimento próximo do senso comum. Os alunos descreveram como microrganismos/micróbios: "Um tipo de ser presente no mundo", "Larvas", "Corpos invisíveis a olho nu”, "Moléculas pequenas", "Partículas", "São umas coisas que temos no corpo", "Pequenos elementos que estão em tudo o que fazemos", "Coisas que a gente não vê", "Seres pequenos que vivem em células", "Micróbios multicelulares".

Alguns alunos fizeram descrições de microrganismos/micróbios parcialmente corretas, agrupadas na Categoria N2: "Células", "Micróbios", "Fungos", "Seres vivos que ajudam ou prejudicam no modo de defesa do nosso corpo contra 
bactérias", "Seres vivos pequenos que vivem em vários lugares", "Pequenos seres que vivem em nosso organismo", "São germes", Organismos pequenos", "Seres vivos compostos por células", "Bichinho pequeno que deixa sua boca podre", "Organismos que existem no ar", "Microbactérias que temos no corpo", "São vírus que podem ser transmitidos ao comermos ou até encostarmos em algo", "São germes que provocam doenças", "Bactérias que prejudicam nosso corpo".

Apenas 10\% descreveram o conceito correto de microrganismos e nenhum estudante descreveu o conceito correto de micróbios. Na Categoria N3, as respostas foram: "Organismos que não podem ser vistos a olho nu", "Рequenos seres vivos que fazem o bem e o mal", "Seres vivos que se alimentam de nutrientes, conhecidos como fungos, bactérias, etc.", "Bactérias, fungos, algas e protozoários, são pequenos seres vivos", "Bichinhos que podem ser vistos com microscópio", "É o nome científico dos micróbios", "Seres unicelulares que não podem ser vistos a olho nu".

Antes da oficina, a maioria dos alunos pensava que os micróbios são capazes de causar doenças e os microrganismos não, ou que são seres vivos de tamanhos diferentes. Preocupa-nos que um conhecimento adquirido fora do ambiente escolar, arraigado no indivíduo, seja tão difícil de ser reconstruído com bases científicas. Em uma investigação sobre o conceito de microrganismos, realizada com alunos de $3^{\circ}$ ano do Ensino Médio, Albuquerque, Braga e Gomes (2013) concluíram que $48 \%$ têm conceitos errados ou não sabem responder sobre o tema.

A experimentação melhorou significativamente $(p=0,000)$ o percentual de estudantes com respostas N3 sobre o que são microrganismos (de $10 \%$ para $41,4 \%$ ), micróbios (de $0 \%$ para $34,3 \%$ ) e a relação entre os dois ( $0 \%$ para $31,1 \%$ ) (Figura 2). 
Figura 2 - Conceito de micróbios, microrganismos e a relação entre os dois

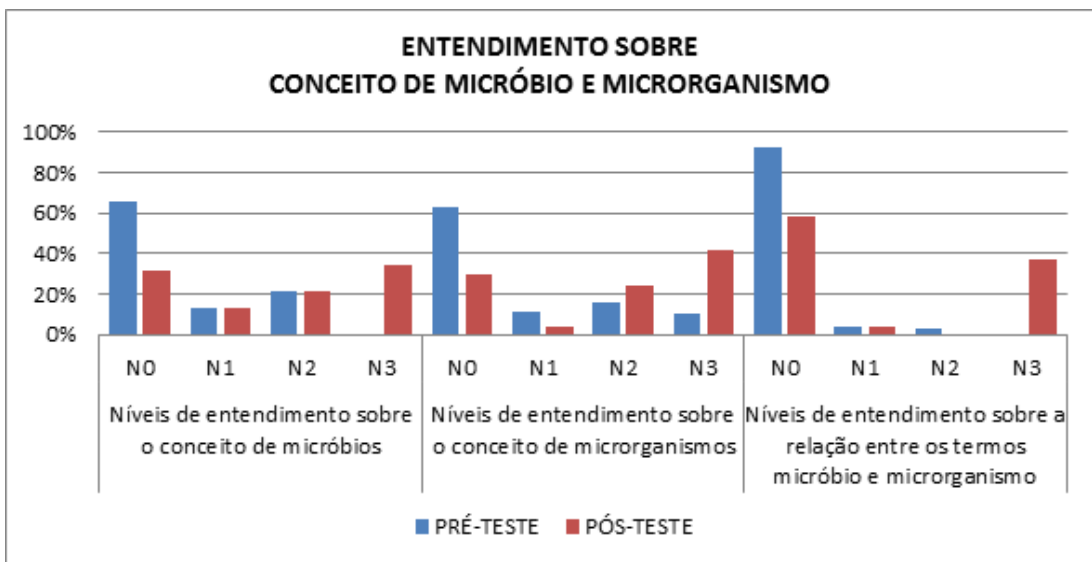

Fonte: Pesquisa com estudantes do Ensino Fundamental. Autoria própria

Dados apresentados a partir do percentual de respostas em cada categoria $(0,1,2,3)$ no pré e pós-teste. $\mathrm{n}=70$. ${ }^{*} \mathrm{p}<0,05$ em relação ao pré-teste.

Após a oficina os estudantes argumentaram que "micróbios e microrganismos são termos diferentes utilizados para designar um grupo de seres vivos que não podem ser vistos a olho nu", ou ainda que "o termo micróbio é mais popular entre os indivíduos leigos e o termo microrganismo é usado no meio escolar e acadêmico".

\section{BLOCO 3 - Ubiquidade dos microrganismos:}

Embora o entendimento de que os microrganismos são capazes de crescer em diversos ambientes ter sido expresso pela maioria dos estudantes, muitos associavam ambientes aparentemente limpos à "esterilidade". Com isso, foi possível compreender os limites da compreensão em relação a conceitos como limpeza, assepsia, desinfecção, esterilidade e colonização, termos frequentemente ouvidos no cotidiano. 
Conforme mostra a Figura 3 - antes da oficina um percentual de estudantes acreditava que não existiam microrganismos em alguns locais específicos. Com a realização do Experimento 3, muitos deles conseguiram modificar suas concepções, sabendo que, nesse caso, as percepções espontâneas dos estudantes são incompatíveis com a concepção científica e que deverão ser substituídas.

Figura 3 - Ubiquidade dos microrganismos. $n=70$

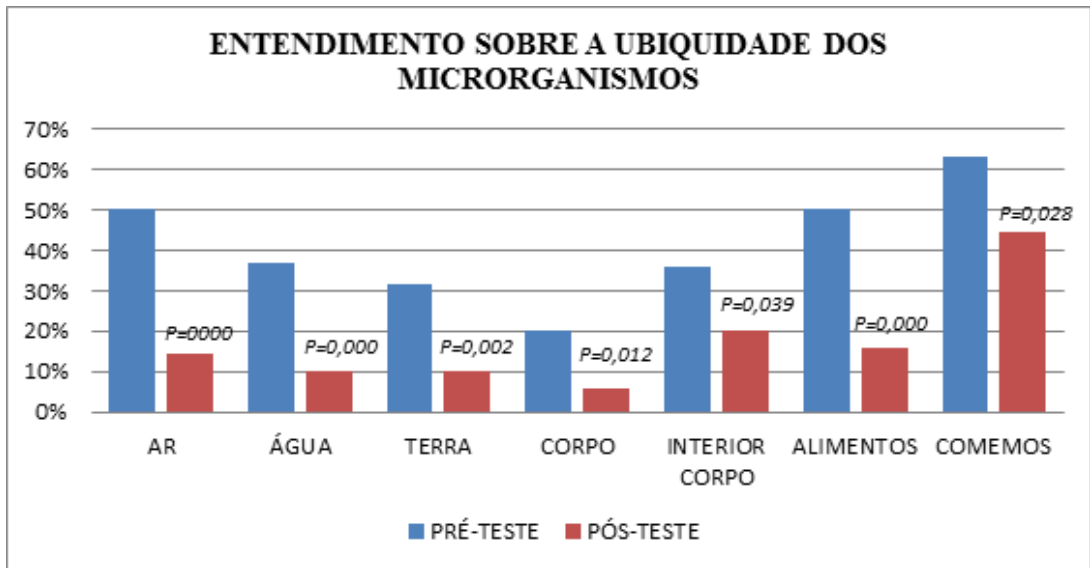

Fonte: Pesquisa com estudantes do Ensino Fundamental. Autoria própria

Dados apresentados a partir do percentual de respostas em cada categoria no pré-teste e pós-teste. ${ }^{*} \mathrm{p}<0,05$ em relação ao pré-teste.

BLOCO 4 - Fatores importantes para o crescimento microbiano:

O que os micróbios precisam para viver?

Antes da oficina, 50\% dos estudantes não souberam responder a essa questão ou deram respostas incorretas (N0). Agrupamos na Categoria N1, 15\% das respostas, mencionando que os micróbios precisam de "sujeira", "ferida", "poluição", "comida", "células vivas", "nosso ser ou o que ele come”, "de ser vivo", "restos de alimentos". 
Depois das aulas experimentais, principalmente a de cultivo dos microrganismos, diminuiu para 20\% ( $p=0,000)$ o percentual das respostas N0 (). Na Categoria N2, 25\% dos estudantes citaram pelo menos um fator importante para o crescimento microbiano. Respostas agrupadas na Categoria N3 foram apontadas por $11 \%$ dos alunos, que mencionaram dois ou mais fatores importantes para o desenvolvimento dos microrganismos, como, "Calor, água e alimentação", "Nutrientes e temperatura adequada", "Calor baixo e proteínas", "Lugar fechado e quente", "Comida, ar e não muito frio", ou "Alimento orgânico".

\section{Do que os micróbios se alimentam?}

Ao investigarmos as concepções prévias dos alunos, verificamos que $47 \%$ não souberam responder a essa questão (N0), 19\% das respostas ficaram na categoria N1, por exemplo, se alimentam de "sujeira", "coisas estragadas", "lixo", "sangue", "terra". Poucos estudantes demonstraram entendimento passível de ser categorizado como N2 (6\%) e N3 (1\%) (Figura 4).

A preparação do meio de cultura para o cultivo microbiano com material conhecido dos alunos colaborou para aumentar para 19\% $(p=0,000)$ o percentual de estudantes com respostas na Categoria $\mathrm{N} 3$, afirmando que os microrganismos se alimentam de "matéria orgânica" ou que "fazem decomposição".

\section{O que pode causar a morte dos micróbios?}

Antes da oficina, $42 \%$ não souberam responder a essa questão (N0). Um único estudante demonstrou entendimento $(\mathrm{N} 3)$ sobre os fatores que levam à morte desses seres. Após as atividades experimentais, a compreensão de que existem fatores físicos e químicos capazes de matar microrganismos melhorou significativamente $(p=0,000)$, somente $12 \%$ dos estudantes não souberam responder (N0). Um alto percentual $(38,6 \%)$ soube citar pelo menos um fator físico ou químico capaz de matar os microrganismos, como "calor", "álcool”, "vinagre", "falta de oxigênio", "falta de alimentos", "produtos antissépti- 
cos", "desinfetantes", "antimicrobianos". O percentual de estudantes capaz de descrever dois ou mais fatores com poder antimicrobiano (N3) subiu de $1 \%$ para $19 \%$.

Figura 4 - Fatores de crescimento microbiano

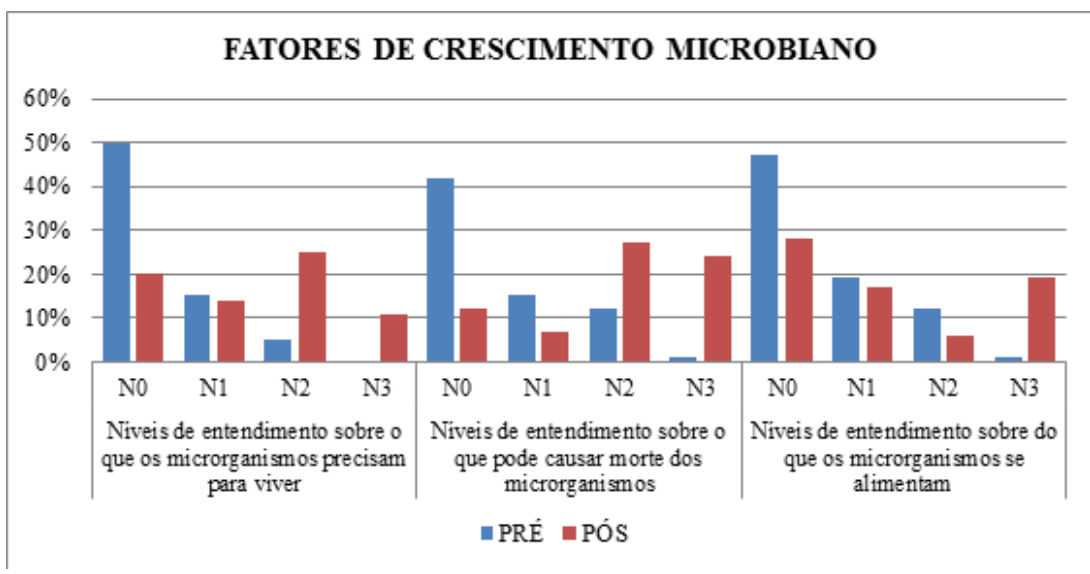

Dados apresentados a partir do percentual de respostas em cada categoria (N0, N1, N2, N3) no pré-teste e pós-teste. $n=70$. *p<0,05 em relação ao pré-teste.

Em relação à aprendizagem sobre os fatores importantes para o crescimento dos microrganismos, observamos que os alunos demonstravam pouco ou nenhum conhecimento para interagir com o conhecimento escolar. Foi notório que a participação ativa dos alunos, ao realizarem os experimentos de preparação de meio de cultura, cultivo de bactérias e fungos do ambiente, teste de antimicrobianos, invocou alguns conceitos relacionados aos fatores necessários à vida de qualquer ser vivo. Essas concepções foram fundamentais como ligações para o entendimento dos microrganismos como seres vivos e, portanto, portadores dessas mesmas necessidades. 
BLOCO 5 - Importância dos microrganismos:

Por que é importante estudar os micróbios?

Como pode ser observado na Figura 5, no pré-teste 52,9\% dos estudantes não souberam explicar o porquê de estudar microbiologia (N0) e 22,9\% deram respostas como: "Obtermos conhecimento", "Saber sobre eles", "Saber se eles podem ser bons", "Gosto de aprender", "Porque é uma coisa interessante", agrupadas na Categoria N1. As respostas de $21,4 \%$ dos estudantes, agrupadas na Categoria N2, indicaram que o estudo dos micróbios é importante: "Porque são seres vivos", "Vencer eles e ter uma cidade sem micróbios", "Para achar a cura para doenças", "Sabermos dos perigos que causam", "Porque nos fazem mal", "Para não pegar nenhum", "Saber combatê-los", "Para não sermos contaminados", "Para proteger nossa saúde", "Prevenção", "Relacionado à doença", "Sabermos dos perigos que causam", "Prevenir doenças", "Entender as doenças e prevenir para que os micróbios não afetem nosso corpo".

De modo geral, esse grupo de alunos descreveu os microrganismos como agentes causadores de doenças, deixando clara a inexistência de concepções acerca da sua função na natureza. Estudos recentes sobre a mesma temática também fizeram tais constatações (SILVA; BASTOS, 2012; BRUM; DA SILVA, 2015). Provavelmente esse resultado se deva à grande influência da mídia sobre as concepções dos alunos (BRUM; DA SILVA, 2015).

Será que eles fazem alguma coisa boa? Exemplifique

Ao solicitar algum exemplo de benefício dos microrganismos, 64,3\% dos estudantes não souberam responder, $30 \%$ deram respostas como: "Eles matam elementos ruins", "Sustentar o corpo", "Combatem os micróbios", "Podem nos ajudar a matar doenças e vírus", "Alguns fazem o bem", "Protegem o corpo", "Protegem nosso corpo", "Ajudam no nosso corpo". 
Figura 5 - Importância dos microrganismos

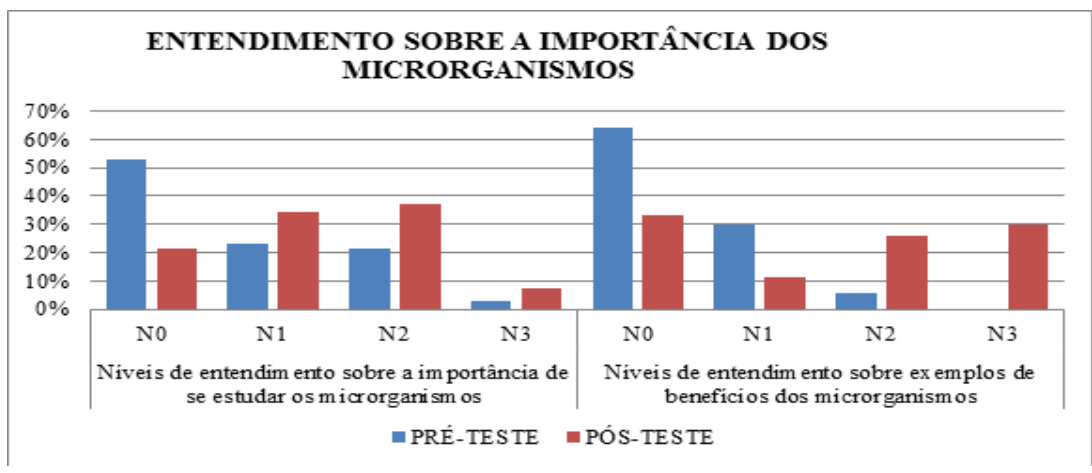

Fonte: Pesquisa com estudantes do Ensino Fundamental. Autoria própria

Dados apresentados a partir do percentual de respostas em cada categoria $(0,1,2,3)$ no pré-teste e no pós-teste. $\mathrm{n}=70 * \mathrm{p}<0,05$ em relação ao pré-teste.

Após as aulas experimentais, principalmente a aula sobre fermentação, quando vários exemplos de utilização dos microrganismos na indústria alimentícia e farmacêutica foram discutidos, o percentual de alunos que soube indicar a importância de se estudar os microrganismos melhorou consideravelmente ( $p=0,000): 25,7 \%$ deles passaram a citar pelo menos um exemplo de benefícios dos microrganismos. Essas respostas foram categorizadas como $\mathrm{N} 2(p=0,000)$. Já 30\% dos alunos, cujas respostas foram agrupadas na Categoria N3, citaram mais de um benefício dos microrganismos: "Nos protegem das bactérias ruins", "Alimentos", "Remédios", "Pão", "Fermento", "Proteger e produzir alimentos", "Decomposição", "Iogurte", "Avisam quando alimento estragou”, "Ajudam a digerir os alimentos", "Decomposição e fabricação de alguns alimentos", " $O$ fermento, por exemplo, produz um gás carbônico que faz o pão que comemos crescer", "Fermentam e ajudam meio ambiente". 
BLOCO 6 - Noções sobre células:

\section{O que é uma célula?}

Antes da oficina, 70\% dos estudantes não demonstraram entendimento conceitual sobre célula. Vários alunos (20\%) relacionavam a célula somente com a constituição do próprio corpo. Somente $10 \%$ descreveram que as células formam todos os seres vivos. Ao final da oficina, $28,6 \%$ dos estudantes $(p=0,020)$ passaram a compreender a célula como estrutura presente em todos os seres vivos. Outro estudo também identificou conceitos não compatíveis com o saber científico sobre células e atribuiu esses resultados à falta de conhecimento da Teoria Celular (SEPEL; ROCHA; LORETO, 2009).

A compreensão de que os microrganismos são seres vivos e, por isso, formados por células, foi investigada por meio de duas questões objetivas. A primeira delas solicitava que os alunos marcassem com um $\mathrm{x}$ as alternativas em que acreditassem conter um ser vivo. A segunda questão demandava que os alunos marcassem as alternativas que contivessem seres formados por células.

Como mostra a Figura 6 - alguns alunos, independentemente da série, afirmaram que micróbios, bactérias, microrganismos e mofos não são seres vivos nem são formados por células. Um dado impressionante é que $46 \%$ dos estudantes não entendem que o mofo é um ser vivo. Esse percentual diminuiu para $21 \%(p=0,000)$ após a oficina.

Percebemos que um conceito básico como o de que os microrganismos são seres vivos formados por células ainda não foi construído por muitos estudantes do $6^{\circ}$ e do $8^{\circ}$ ano. Esse dado é preocupante, pois sabemos que conceitos embasadores da ciência são necessários para que o aluno seja capaz de analisar e interpretar fenômenos. 
Figura 6 - Microrganismos como seres vivos
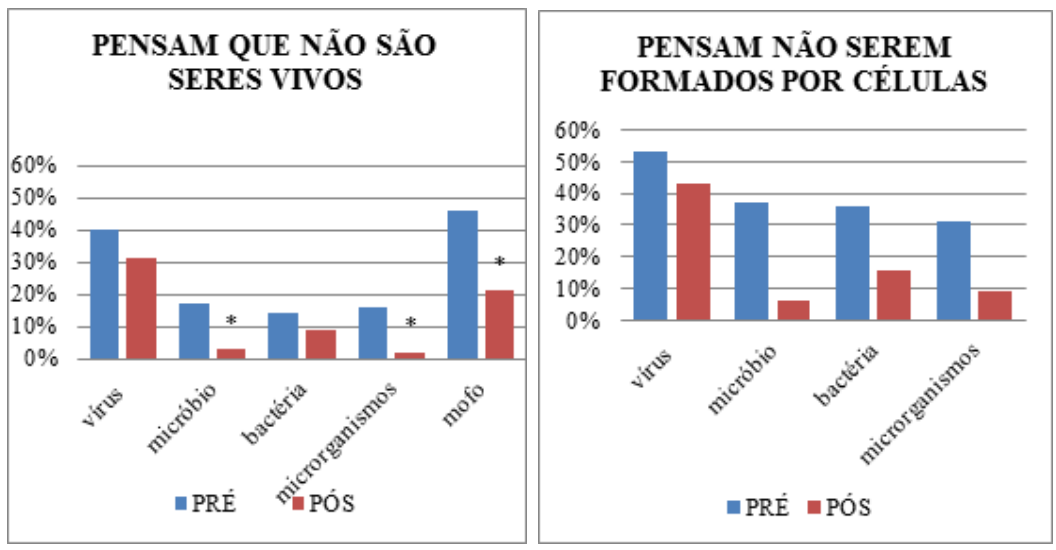

Fonte: Pesquisa com estudantes do Ensino Fundamental. Autoria própria

Entendimento sobre classificação e estrutura celular dos microrganismos. A. alunos que negam a relação desses organismos com os seres vivos. B. alunos que negam que esses organismos sejam formados por células. ${ }^{*} \mathrm{p}<0,05$ em relação ao pré-teste.

\section{Desempenho Geral do Aluno}

Houve uma melhora significativa no escore geral dos estudantes após a oficina. No pré-teste, a média geral dos alunos foi de 18,0 066,0 e no pós-teste foi de 30,4 $\pm 9,2(p=0,000)$, melhorando em 66,67\%. Apenas dois alunos não melhoraram suas notas no pós-teste. A reelaboração de algum conceito foi observada nos outros $97 \%$ dos alunos, que ao descreverem seu entendimento sobre os temas tratados aproximaram-se das definições presentes na literatura científica, utilizando-se de palavras de seu próprio vocabulário. Esse efeito positivo aconteceu pela participação ativa na construção do saber (FREEMAN, 2014); pela interação com os colegas, professores ou outros materiais de pesquisa (DA SILVA; DORNFELD, 2016); pela construção de "memória episódica" que pode dar suporte ao desenvolvimento de conhecimento conceitual (WHITE, 1991). 
Nesta pesquisa, no pré-teste $57 \%$ dos alunos ficaram com escore abaixo da média de 18,01 . No pós-teste, houve um aumento da média geral para 30,4 , quando $45,7 \%$ dos alunos ficaram abaixo desta média e somente $10 \%$ continuaram abaixo da média do pré-teste $(18,1)$, mostrando que mesmo com todo o esforço do professor em realizar práticas de ensino diferenciadas, alguns alunos não têm melhora significativa nos escores dos testes. $\mathrm{O}$ envolvimento $\mathrm{e}$ as atitudes dos alunos durante as aulas influenciam a decisão do professor em preparar atividades diferenciadas. O professor, muitas vezes, deseja realizar esse tipo de atividade, mas se desmotiva com a falta de interesse de alguns alunos em detrimento daqueles interessados.

Em todas as turmas percebemos interesse e motivação da maioria dos estudantes pelas atividades, por exemplo, com questionamentos sempre vinculados à promoção da saúde. Alguns alunos, que não mostravam interesse durante os experimentos na escola, ficaram mais animados com a visita à universidade. Conforme relato dos estudantes, a maioria nunca havia tido contato com um laboratório até a Oficina Micromundo.

Figura 7 - Médias dos escores obtidos a partir do somatório das notas de todos os participantes da Oficina. $n=70$

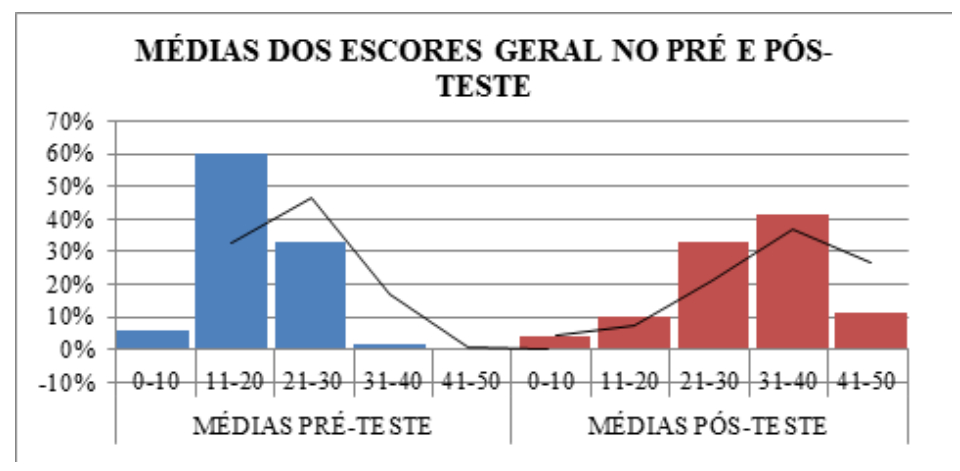

Fonte: Pesquisa com estudantes do Ensino Fundamental. Autoria própria

Não observamos diferença significativa entre as médias dos estudantes do $6^{\circ}$ e do $8^{\circ}$ ano. Conforme mostra a Figura 8 - é possível observar que houve diferença significativa entre os escores das escolas, tanto no pré-teste quanto 
no pós-teste $(p=0,040)$. Provavelmente esse resultado deva-se a diferenças no nível socioeconômico dos estudantes de cada uma delas, o que vai ao encontro dos dados dos Relatórios do Enem (INSTITUTO..., 2016).

Figura 8 - Percentual de estudantes categorizados conforme a nota do pré e pós-teste para cada escola

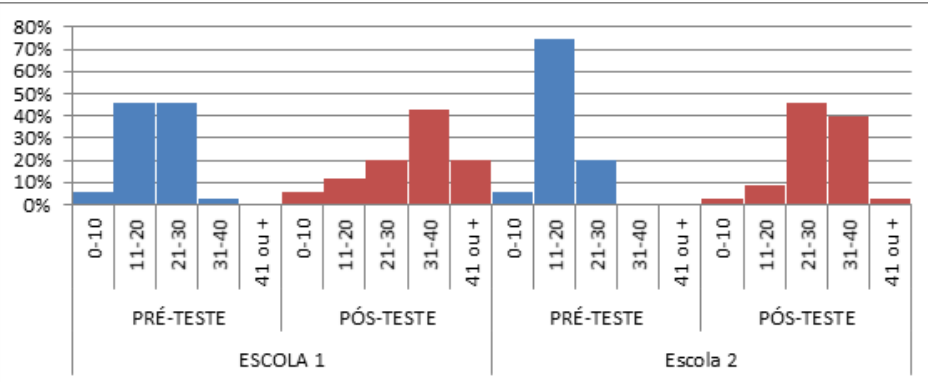

Fonte: Pesquisa com estudantes do Ensino Fundamental. Autoria própria.

\section{Considerações Finais}

A experimentação por si só não é garantia de aprendizagem. Durante uma aula experimental, vários são os meandros para o seu sucesso como metodologia de ensino. É importante privilegiar o raciocínio crítico, estimular a criatividade, observação, e não somente a ação mecânica. $O$ desenvolvimento cognitivo é favorecido pela dinâmica do trabalho e discussão em grupo, pois junto com a aprendizagem, propiciam sentimentos de alegria, bem-estar e felicidade (DA SILVA; DORNFELD, 2016). Para Gaspar (2005), as vantagens da estratégia experimental estão na discussão da ideia central do experimento, na riqueza da interação social que ela desencadeia e na possibilidade de propiciar um maior envolvimento, estimulando o aluno a arriscar previsões, o que dificilmente acontece nas aulas teóricas.

A partir da análise dos questionários do pré-teste, percebemos que os estudantes foram capazes de resgatar conceitos presentes na sua estrutura cognitiva sobre o mundo microbiano, entretanto ficou evidente que boa parte desses conceitos era incompleta ou incompatível com os saberes científicos. 
Os experimentos sobre os microrganismos provocaram conflitos entre esses conceitos e os problemas apresentados. Nesse espaço de desequilíbrio, criamos condições para novos esquemas que levaram à aprendizagem.

Percebemos ser comum que os alunos continuem argumentando sobre as atividades diárias envolvendo microrganismos usando as suas concepções alternativas, embora tenham tido contato como conhecimento científico envolvido nessas ações. Por exemplo, ainda que entendam que a biodeterioração das frutas é um processo de decomposição causado por fungos e bactérias, não usam essa linguagem cotidianamente. Ou ainda, mesmo sabendo da existência de diferentes grupos de seres vivos referidos por micróbios, continuam generalizando esse termo. Supostamente, o cenário apresentado neste trabalho é o mesmo de muitas outras escolas, ou seja, o conhecimento dos alunos sobre microbiologia é resultado de um ensino baseado na memorização de conteúdos. Na medida, entretanto, em que novos conceitos vão sendo incorporados às estruturas cognitivas dos alunos e adquirem significado a partir das suas concepções, podemos afirmar que a aprendizagem, de fato, aconteceu (PELIZZARI, 2002; NARDI; GATTI, 2004).

Sob a ótica da teoria construtivista de Jean Piaget (1896-1980), as crianças constroem os conceitos científicos como consequência da aplicação do pensamento lógico, resultado da interação com objetos e fenômenos. O sujeito começa a desenvolver conceitos sobre os fenômenos naturais ainda antes da instrução formal e chega à escola com entendimentos prévios sobre os conceitos científicos que lá irá aprender (JONES; RUA, 2006). Esse entendimento, que pode ser ou não consistente com o conhecimento científico, embasa as explicações que o aluno formulará diante das experiências cotidianas. Alguns trabalhos mostram que os alunos podem manter concepções alternativas simultaneamente aos novos conceitos científicos (MORTIMER, 1996; POSNER, 1982).

Com aulas experimentais envolvendo coleta de microrganismos do ambiente, utilização de produtos antimicrobianos e procedimentos de desinfecção e fermentação, os alunos estabelecem conexões com suas experiências de vida. Além do conflito cognitivo, essa conexão faz com que eles se tornem engajados com o problema em questão e se esforcem para entendê-lo e solucioná-lo 
(FASS, 2004 ). Foi notório o quanto a experimentação influenciou positivamente a aprendizagem sobre microrganismos, visto que os alunos vivenciaram temas que, quando trabalhados em aulas teóricas, são extremamente abstratos.

Após participarem da oficina experimental Micromundo, a maioria dos estudantes foi capaz de entender o que são microrganismos, como vivem, onde estão, sua importância e também sua constituição celular. Houve uma melhora de $66,67 \%$ na média geral do desempenho desses estudantes.

Isso posto, atividades experimentais são estratégias indispensáveis para melhorar o aprendizado de microbiologia. Em consequência disso, legitimamos a necessidade de organização de espaços adequados e o aperfeiçoamento dos professores para a real efetivação desse tipo de prática nas escolas.

\section{Referências}

ALBUQUERQUE, G. G.; BRAGA, R. P. D. S.; GOMES, V. Conhecimento dos alunos sobre microrganismos e seu uso no cotidiano. Revista de Educação, Ciências e Matemática, 2, n. 1, 2013.

AZEVEDO, T. M.; SODRÉ, L. Conhecimento de estudantes da educação básica sobre bactérias: saber científico e concepções alternativas. Revista de Educação, Ciências e Matemática, v. 4, n. 2, 2014.

BARBERÁN, A. et al. Microbes Should Be Central to Ecological Education and Outreach. Journal of microbiology \& biology education, v. 17, n. 1, p. 23, 2016.

BARDIN, L. Análise de conteúdo. 70. ed. São Paulo: Almedina Brasil, 2011. 279 p.

BODELIER, P. Toward understanding, managing, and protecting microbial ecosystems. Frontiers in microbiology, v. 2, p. 80, 2011.

BRASIL. Ministério da Educação e Cultura. Parâmetros Curriculares Nacionais - Ciências Naturais. Brasília: MEC; SEF, 1997.

BRUM, W. P.; DA SILVA, S. D. C. R. As concepções de estudantes do ensino fundamental sobre bactérias e suas relações com a saúde humana. Revista Ciências \& Ideias, v. 6, n. 2 , p. $60-70,2015$.

BYRNE, J.; SHARP, J. Children's ideas about micro-organisms. School science review, v. 88, n. 322, p. 71-79, 2006. 
CÂNDIDO, M. D. et al.. Microbiologia no ensino médio: analisando a realidade e sugerindo alternativas de ensino numa escola estadual paraibana. Ensino, Saúde e Ambiente, v. 8, n. 1, 2015.

CARNEIRO, M. R. P. et al. Percepção dos alunos do ensino fundamental da rede pública de Aracaju sobre a relação da Microbiologia no cotidiano. Scientia Plena, v. 8, n. 4a, 2012.

CARVALHO, Anna Maria Pessoa de. O ensino de Ciências: unindo a pesquisa e a prática. São Paulo: Ed Thompson, 2004.

CONSORTIUM, H. M. P. Structure, function and diversity of the healthy human microbiome. Nature, v. 486, n. 7.402, p. 2.007-2.014, 2012.

DA SILVA, D. T.; DORNFELD, C. B. Dinâmicas de grupo em aulas de biologia: uma proposta motivacional para a aprendizagem. Revista electrónica de enseñanza de las ciencias, v. 15, n. 1, p. 147-166, 2016.

DELIZOICOV, D.; ANGOTTI, J. A. P. Metodologia do ensino de ciência. São Paulo: Cortez, 1990. (Coleção magistério, $2^{\circ}$ grau. Série formação do professor).

FASS, M. F. Connecting Microbiology With the World Outside: Constructing Opportunities for Authentic Learning in the Classroom and the Community. Focus On Microbiology Education, Miami, vol. 10 , n. 2, Winter 2004.

FISHER, M. C.et al. Emerging fungal threats to animal, plant and ecosystem health. Nature, v. 484, n. 7.393, p. 186-194, 2012.

FOLMER, V. E. A. Experimental activities based on ill-structured problems improve Brazilian school students' understanding of the nature of scientific knowledge. Revista Electrónica de Enseñanza de las Ciencias, v. 8, n. 1, p. 232-254, 2009.

FREEMAN, S. et al. Active learning increases student performance in science, engineering, and mathematics. Proceedings of the National Academy of Sciences, v. 111, n. 21, p. 8.410-8.415, 2014.

GALIAZZI, M. D. C. et al. Objetivos das atividades experimentais no ensino médio: a pesquisa coletiva como modo de formação de professores de ciências. Ciência \& Educação, Bauru, v. 7, n. 2, p. 249-263, 2001.

GALIAZZI, M. D. C.; GONÇALVES, F. P. A natureza pedagógica da experimentação: uma pesquisa na licenciatura em química. Química Nova, v. 27, n. 2, p. 326-331, 2004.

GASPAR, Alberto; DE CASTRO MONTEIRO, Isabel Cristina. Atividades experimentais de demonstrações em sala de aula: uma análise segundo o referencial da teoria de Vygotsky. Investigações em Ensino de Ciências, v. 10, n. 2, p. 227-254, 2016.

GOLDSCHMIDT, A. I. et al. Investigação das concepções sobre higiene e uso de metodologias alternativas. Amazônia: Revista de Educação em Ciências e Matemáticas, v. 10, n. 19, 2015. 
HOFSTEIN, A.; KIND, P. M. Learning in and from science laboratories. In: Second international handbook of science education. Springer Netherlands, p. 189-207, 2012.

HOFSTEIN, A.; LUNETTA, V. The labortory in science education: foundations for the twenty-first centrury. Science education, 88.1, p. 28-54, 2004.

INSTITUTO NACIONAL DE ESTUDOS E PESQUISAS EDUCACIONAIS ANÍSIO TEIXEIRA - INEP. IDEB, Índice de desenvolvimento da Educação Básica, disponível em http://ideb.inep.gov.br/resultado/home.seam?cid=967574

JONES, M. G.; RUA, M. J. Conceptions of germs: expert to novice understandings of microorganisms. Electronic Journal of Science Education, v. 10, n. 3, 2006.

LUNETTA, V. N.; HOFSTEIN, A.; CLOUGH, M. P. Learning and teaching in the school cience laboratory: An analysis of research, theory, and practice. Handbook of Research on Science Education, p. 393-441, 2007.

MAFRA, P.; LIMA, N.; CARVALHO, G. S. D. Seminário Internacional de Educação Microrganismos e saúde no $1^{\circ}$ e $2^{\circ}$ ciclos do ensino básico: perceções das crianças, 9 . Seminário Internacional de Educação Física, Lazer e Saúde: desafios e oportunidades num mundo em mudança, 9., v. 1, p. 856-868, 2013. [S.1.]: [s.n.], p. 856-868, 2013.

MORTIMER, E. F. Construtivismo, mudança conceitual e ensino de ciências: para onde vamos. Investigações em ensino de ciências, v. 1, n. 1, p. 20-39, 1996.

NARDI, R.; GATTI, S. R. T. A review of the constructivist research in the last decades: spontaneous reasoning, conceptual change and science education. Ensaio Pesquisa em Educação em Ciências, Belo Horizonte, v. 6, n. 2, p. 115-144, 2004.

NETO, J. M.; FRACALANZA, H. O livro didático de ciências - problemas e soluções. Science texbooks: problems and solutions. Ciência \& Educação, v. 9, n. 2, p. 147-157, 2003.

ORGANISATION FOR ECONOMIC CO-OPERATION AND DEVELOPMENT. Pisa 2012 - Assessment and Analytical Framework: Mathematics, Reading, Science, Problem Solving and Financial Leteracy. [S.1.], 2013. . Results from PISA 2015. OECD. [S.1.], 2016.

PELIZZARI, A. et al. Teoria da aprendizagem significativa segundo Ausubel. Revista $P E C$, v. 2, n. 1, p. 37-42, 2002.

PIAGET, J.; DELVAL, J. A. La epistemología genética. [S.1.]: A. Redondo, 1970.

POSNER, G. J. et al. Accommodation of a scientific conception: Toward a theory of conceptual change. Science education, v. 66, n. 2, p. 211-227, 1982.

ROBERTSON-ALBERTYN, S.; HARDEE, E.; STANLEY-WALL, N. R. Microbe Motels: An Interactive Method to Introduce the Human Microbiome. Journal of microbiology \& biology education, v. 17, n. 2, p. 282, 2016.

ROCHA, J. B. T.; SOARES, F. A. O ensino de ciências para além do muro do construtivismo. Ciência e Cultura, 4, p. 26-27, 2005. 
SCHAECHTER, M.; KOLTER, R.; RILEY-BUCKLEY, M. S. Microbiology in the 21st Century: Where are We and where are We Going? American Academy of Microbiology, p. 1-21, 2004.

SEPEL, L. M. N.; ROCHA, J. B.; LORETO E. L. S. Using a Replica of Leeuwenhoek's Microscope to Teach the History of Science and to Motivate Students to Discover the Vision and the Contributions of the First Microscopists. CBE-Life Sciences Education, v. 8, p. 338-343, 2009.

SILVA, M. S. D.; BASTOS, S. N. D. Ensino de microbiologia: percepção de docentes de discentes nas escolas públicas de Mosqueiro, Belém, Pará. III ENCONTRO NACIONAL DE ENSINO DE CIÊNCIAS DA SAÚDE E DO MEIO AMBIENTE-UFF, 3., Niterói, RJ: [s.n.], 2012.

WHITE, R. T. Episodes, and the purpose and conduct of practical work. In: WOOLNOUGH, B. E. Practical science. UK: Open University Press, 1991. p. 78-86. 